\title{
Culture Matters: A Study on Presence in an Interactive Movie
}

\author{
Jun Hu, Ph.D. and Christoph Bartneck, Ph.D.
}

\begin{abstract}
A cross cultural study was conducted to test the influences of different cultural backgrounds on the user's presence experience in interacting with a distributed interactive movie. The effects of embodied interaction on presence were also investigated because embodiment is often used to enrich the experience and to reduce the complexity of distributed interaction. In absence of a clear definition of what cultural factors might influence presence, Dutch and Chinese participants were invited to the study to optimize cultural diversion. The results suggested that Chinese participants perceived more presence than Dutch participants in all conditions. The results also show that interaction methods (direct touch against remote control) had no influence, while embodiment (robot against screen agent) had mixed effects on presence.
\end{abstract}

\section{Introduction}

$\mathbf{T}$ HE USER'S CHARACTER is believed to influence the user's feeling of presence. The user's cultural background is often mentioned as such a characteristic. ${ }^{1,2} \mathrm{~A}$ few cross-cultural presence studies are available, ${ }^{3}$ but none investigated the relationship between the user's cultural background and presence directly. As Sas and O'Hare ${ }^{4}$ pointed out, a "large amount of work has been carried out in the area of technological factors affecting presence. . . . Comparatively, the amount of studies trying to delineate the associated human factors determinant on presence is significantly less." This influence of culture on presence is more of a conjecture than a proven fact, and therefore we conducted an empirical study to investigate the relationship.

In absence of a clear definition of what cultural factors may influence presence, a good approach is to include participants from clearly different cultures. Using Dutch and Chinese participants in our study optimized cultural diversion. Hofstede ${ }^{5}$ provides an empirical framework of culture by defining several dimensions of culture. China and the Netherlands differ substantially on all dimensions except uncertainty avoidance (see Table 1). Power distance, for example, refers to the extent to which less powerful members expect and accept unequal power distribution within a culture. The Netherlands rank very low on this dimension, while China ranks very high. It is also reported ${ }^{6}$ that agreeableness, one of the Big Five personality traits, ${ }^{7}$ is positively associated with spatial presence. The discussion about the con- nection between personality traits and culture is controversial. Still, the Chinese culture does include the very important concept of harmony, which appears to be closely related to agreeableness. Harmony is so deeply embedded into Chinese culture that it is unlikely not to result in more agreeableness.

At the same time, we were interested in distributed interactive media and their influences on presence. In the vision of ambient intelligence, ${ }^{8}$ the next generation of people's interactive media experience will unfold not only on a computer or television, or in a head set, but in the whole physical environment. The environments involve multiple devices that enable natural interactions and adapt to the users and their needs.

Formerly, distribution referred only to the distribution of data or computational processes in a network. Previous systems already employed distributed presentation to enhance the entertainment experience and thereby increase the immersiveness of the content. Multichannel surround sound systems, for example, distribute sound all around the audience and hence provide a more realistic and natural sound experience. The ambient intelligence ${ }^{8}$ concept goes beyond such sound distributions by distributing content through other channels in the user's environment. Displays in the room may show video clips, lamps may change color and brightness, robots may dance and sing, and couches may vibrate. The light color, robotic behavior, and the couch vibration are parts of delivered content, conveying a virtual experience but with a direct physical embodiment. Ambient 
Table 1. Hofstede's Culture Dimension Scores FOR Dutch AND CHINESE

\begin{tabular}{lcc}
\hline & Dutch & Chinese \\
\hline Power distance & $38 \mathrm{~L}$ & $80 \mathrm{H}$ \\
Individualism & $80 \mathrm{H}$ & $20 \mathrm{~L}$ \\
Masculinity & $14 \mathrm{~L}$ & $50 \mathrm{M}$ \\
Uncertainty avoidance & $53 \mathrm{M}$ & $60 \mathrm{M}$ \\
Long-term orientation & $44 \mathrm{M}$ & $118 \mathrm{H}$ \\
\hline
\end{tabular}

$\mathrm{H}$, top third; $\mathrm{M}$, medium third; L, bottom third (among 53 countries and regions for the first four dimensions; among 23 countries for the fifth)

intelligence is therefore a distinct extension to classical virtual environments.

Such a distributed environment may be perceived differently by members from different cultures. A relevant study ${ }^{9}$ was conducted in which American and Chinese participants viewed photographs. The Chinese tended to look at the whole picture and rely on contextual information when making decisions and judgments about what they saw, whereas the Americans tend to be analytical and pay more attention to the key, or focal, objects in a scene. The Westerners may, for example, concentrate on the woman in the Mona Lisa, while the Easterners may pay more attention to the rocks and sky behind her. This result may be of relevance to distributed environments, in which Chinese participants may take a more holistic view while the Dutch focus more on specific objects.

The distribution of interactive content to multiple devices may also have a negative effect. It may increase the complexity of interaction. To ease the situation, embodied characters, such as $\mathrm{eMuu}^{10}$ or Tony, ${ }^{10,11}$ may be used to give such an environment a concrete face. These characters have a physical embodiment and may present content through their behavior and interact with the user through speech and body language. Moreover, the influence of embodiment on the user's presence experience seems unclear. On the one hand, embodiment extends the distributed content from an onscreen virtual environment to a physical environment. The physical embodiment improves the content's lifelikeness and fidelity by stimulating more sensors of the user. This may result in an increased feeling of presence. ${ }^{12}$ On the other hand, the physical embodiment may transfer more attention from the virtual environment to the physical environment. The physical embodiment may remind the user of its existence in this world and may break down the illusion of "being there" and hence would result in less feeling of presence. ${ }^{1}$ The division of attention itself may also have such an effect.

To control interactive content, the user requires interaction devices. A physical embodiment would invite direct manipulation. A robot could, for example, ask the user to touch its shoulder to select an option. Interaction with a virtual onscreen character may favor the use of a remote control. Embodiment in interactive media can therefore not be studied

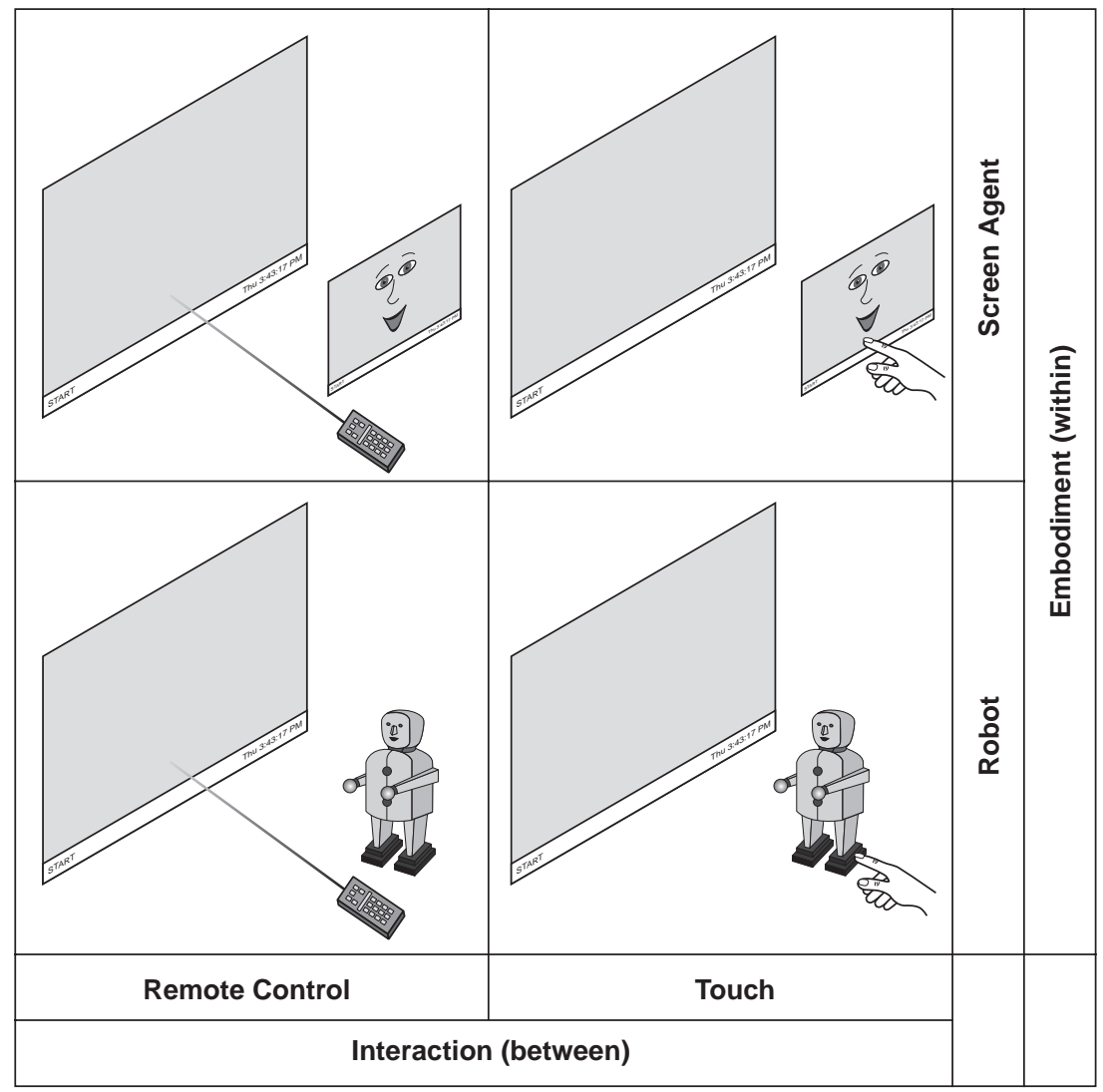

FIG. 1. Conditions of the experiment with Chinese and Dutch participants. 


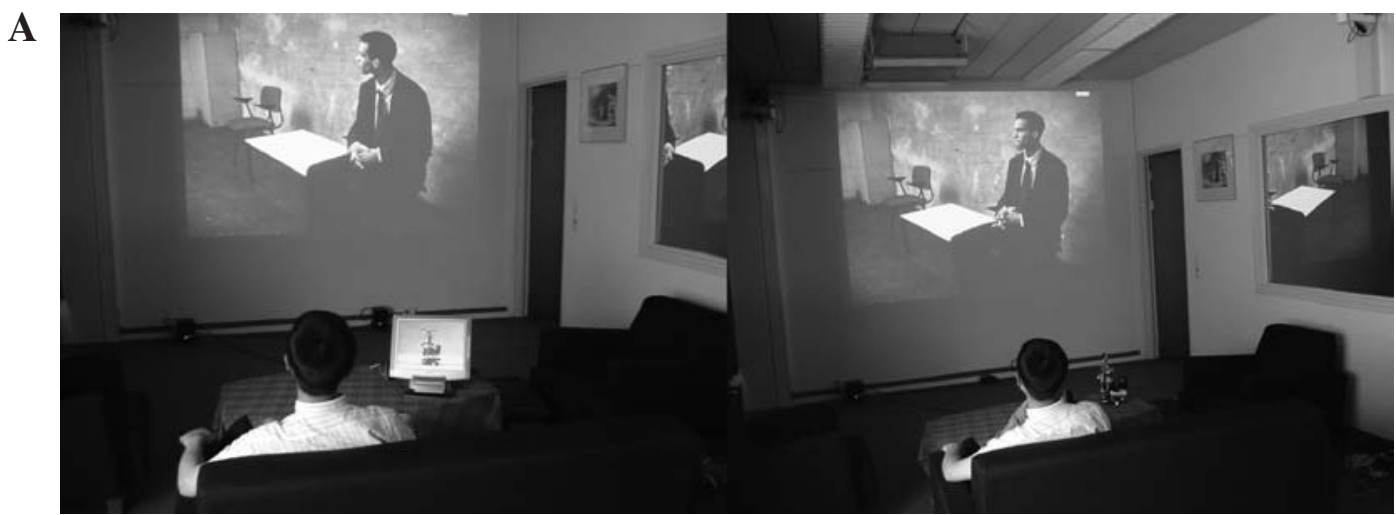

FIG. 2. Experiment setup: (A) ScreenRemote/ScreenTouch, (B) RobotRemote/RobotTouch.

without considering the interaction method. We therefore included two interaction methods in our study.

In this framework of interactive distributed media, we defined the following three research questions: (a) What influence has the user's cultural background on the user's presence experience? (b) What influence does the embodiment of a virtual character have on the user's presence experience? (c) Would directly touching the presented content objects bring more presence than pressing buttons on remote controls?

\section{Experiment}

We conducted a $2 \times 2 \times 2$ (interaction $\times$ embodiment $\times$ culture) mixed between/within experiment (Fig. 1). Interaction and culture were the between-participants factors. Interaction had the conditions RemoteControl and DirectTouch, and culture had the conditions Dutch and Chinese. Embodiment was a within-participants factor. Embodiment had the conditions ScreenAgent and Robot.

\section{Measurements}

The ITC-SOPI ${ }^{13}$ questionnaire was used. Only the definition of the displayed environment in the introduction was adjusted to include the robot/screen character. The Chinese participants had a good understanding of the English language and therefore no validated translation was necessary. The questions remained unchanged and are clustered into four groups: (a) Spatial Presence, a feeling of being located in the virtual space; (b) Engagement, a sense of involvement with narrative unfolding within virtual space; (c) Ecological validity, a sense of the naturalness of the mediated content; (d) Negative Effects, a measure of the adverse effects of prolonged exposure to the immersive content.

\section{Participants}

Nineteen Chinese and 24 Dutch people between the ages of 16 and 48 (14 female, 29 male) participated in the experiment. Most of them were students and teachers from Eindhoven University of Technology, with various backgrounds

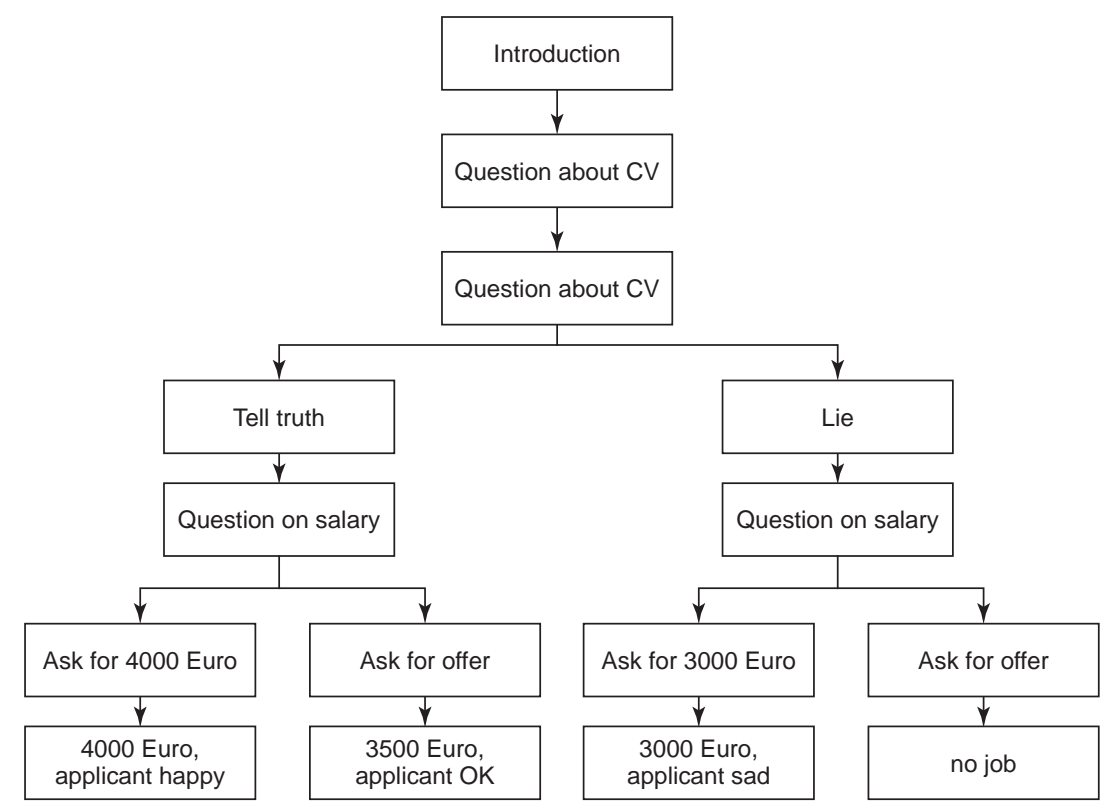

FIG. 3. Storyline. 


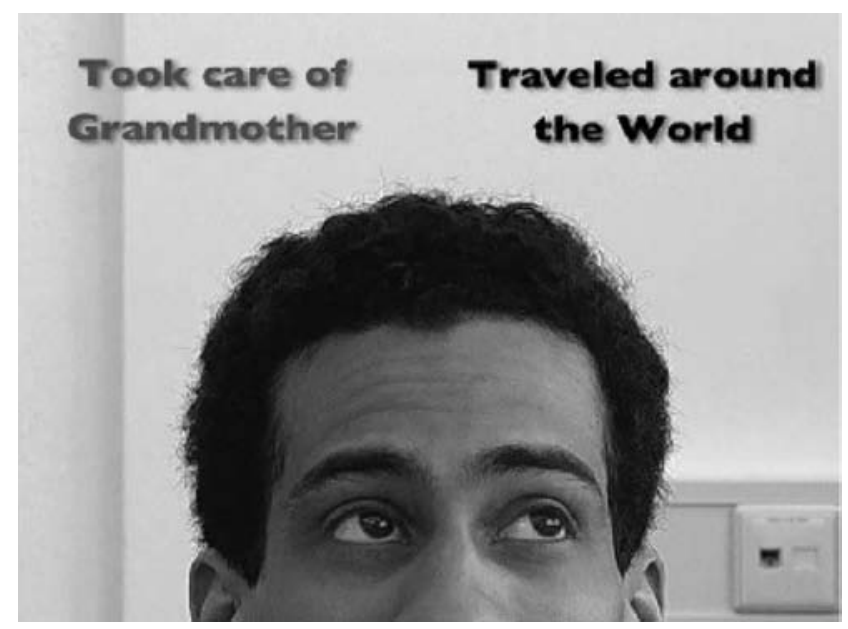

FIG. 4. A decision point.

in computer science, industrial design, electronic engineering, chemistry, mathematics, and technology management. The Chinese participants were no longer than two years in the Netherlands. All participants had good command of the English language and were frequently exposed to Englishspeaking media, such as movies, Web pages, newspapers, and TV shows.

\section{Setup}

Three computers were connected to the public network of Eindhoven University of Technology, with a bandwidth of $10 \mathrm{Mb} / \mathrm{s}$, to serve three presentation terminals. One laptop computer was connected with a projector to serve an MPEG2 movie to a projected screen. The second computer had the same hardware configuration. Two interaction devices were served from this computer: a physical robotic actor, "Tony," through an infrared tower connected to the serial port; and an infrared sensor connected to another serial port that detected the input from a PlayStation 2 remote and ran the central player that read the script and scheduled the presentation tasks. The third computer was connected to a Philips DesXcape Smart Display through a firewalled local network to serve the virtual robot to a touch screen.

The experiment took place in a living room laboratory (Fig. 2). The participants were seated on a couch in front of a table. The coach was $3.5 \mathrm{~m}$ away from the main screen, which was projected onto a wall. The projection had a size of $2.5 \mathrm{~m} \times 1.88 \mathrm{~m}$ with $1400 \times 1050$ pixels. The second screen was a $30 \mathrm{~cm} \times 23 \mathrm{~cm}$ with $1280 \times 1024$ pixels LCD touch screen, located $0.5 \mathrm{~m}$ from the coach, standing on the table.

In the Robot conditions, the secondary touch screen was replaced with the Lego robot that was about the same height. In the ScreenAgent conditions, the secondary screen displayed a full-screen agent of the robot. The behavior of the screen-based agent and the Lego robot were identical. They played the role of a TV companion by looking randomly at the user and the screen, but always looking at the user while speaking. Speakers were hidden under the table and were used to produce the speech, which was based on the standard Apple Speech Synthesis software. At the start of every movie, the character introduced itself and its role.

Since a media content that is acceptable in one culture can be perceived inappropriate, rude, or offensive in another, ${ }^{14}$ the movie was designed to be as culturally neutral as possible. The actors spoke English. This study does not investigate the influence of media content on presence, and therefore the story and movie cuts were neither too exciting nor too boring for both Dutch and Chinese participants. Otherwise, they may have masked the effects of embodiment and culture.

The interactive movie, about approximately 10 minutes, was about a job interview in which the participants had to make decisions for the applicant. The storyline was dis-

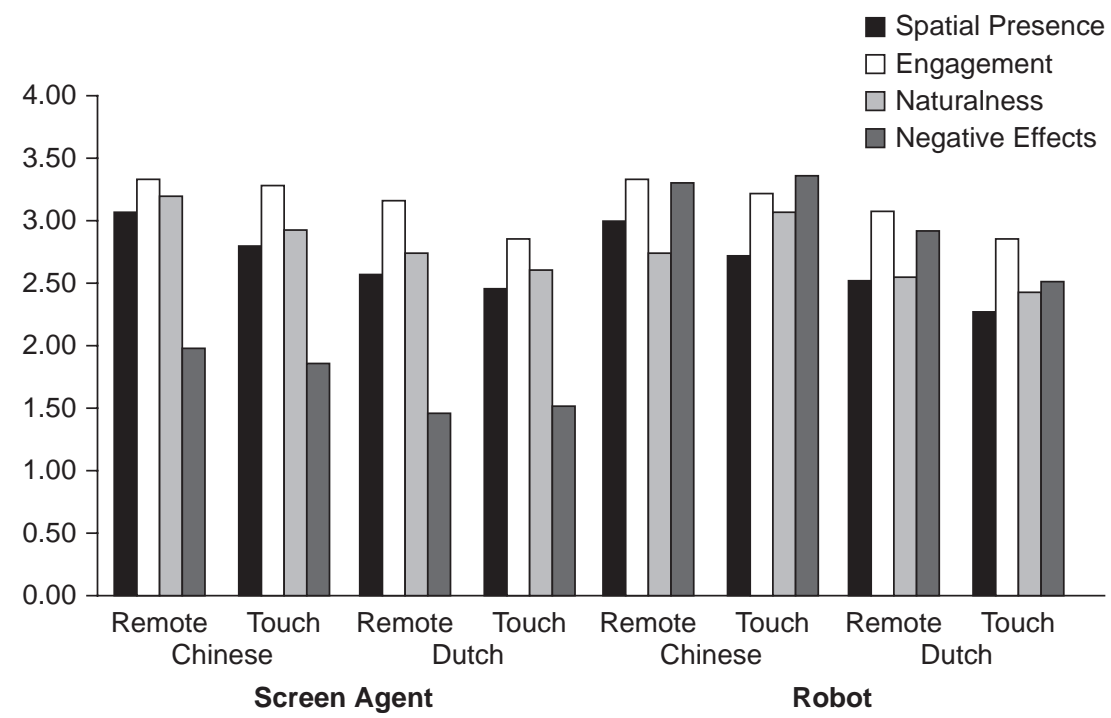

FIG. 5. Means of all measurements in all conditions. 
Table 2. F and P Values for Culture and Embodiment

\begin{tabular}{llcc}
\hline Factor & Measurement & $F(1,39)$ & $p$ \\
\hline Embodiment & Spatial Presence & 4.789 & 0.035 \\
& Engagement & 0.515 & 0.477 \\
& Naturalness & 4.335 & 0.044 \\
& Negative Effects & 119.973 & 0.001 \\
Culture & Spatial Presence & 19.49 & 0.001 \\
& Engagement & 4.962 & 0.032 \\
& Naturalness & 7.494 & 0.009 \\
& Negative Effects & 24.491 & 0.001 \\
\hline
\end{tabular}

cussed with several Chinese and Dutch people to assure that the actions of the characters would be plausible in both cultures. The movie had two decision points, which resulted in four possible movie endings (Fig. 3). The participants chose different options for decisions almost all the time. At every decision point, the camera zoomed in on the applicant's forehead (Fig. 4).

The actor then cycled through two options in his mind. He looked to the left and thought aloud about one option, then he looked right and thought aloud about the second option. In the remote condition, the screen showed one icon on the left and a different icon on the right. The icons were identical to two icons on the remote control. In the robot condition, the participant had to touch the left or right shoulder of the robot to make the decision.

\section{Procedure}

After reading an introduction that explained the structure of the experiment, the participants started with a training session. In this session, the participants watched an unrelated interactive movie that had only one decision point, during which the participants could make the decision using the remote control. They then had the opportunity to ask questions about the process of the experiment. Next, the participants were randomly assigned to one of the between-participants conditions, which each consisted of two movies and a questionnaire after each movie. The participants each received five Euros for their efforts.

\section{Results}

The mean scores for all measurements, including their standard deviations, are presented graphically in Figure 5.

A $2 \times 2 \times 2$ (embodiment $\times$ interaction $\times$ culture) repeated measures ANOVA was conducted. Interaction had no significant influence on any of the measurements. Embodiment and culture both had significant influence on almost all measurements (Table 2). Interaction was removed as a factor from the further analyses because it had no effect on the measurements. The means for all remaining conditions are summarized in Figure 6 and were used as the basis for the further analyses.

Paired sample $t$ tests were performed across both culture conditions. The measurements for Spatial Presence were significantly higher in the ScreenAgent condition, $t(42)=2.235$, $p=0.031$, than in the Robot condition. Negative Effects were significantly higher in the Robot condition, $t(42)=2.38, p=$ 0.022, than in the ScreenAgent condition.

Independent samples $t$ tests were performed. All measurements between the Dutch and the Chinese participants differed significantly except for Engagement in the screen condition, which just missed the significance level: $t(41)=$ 2.007, $p=0.051$.

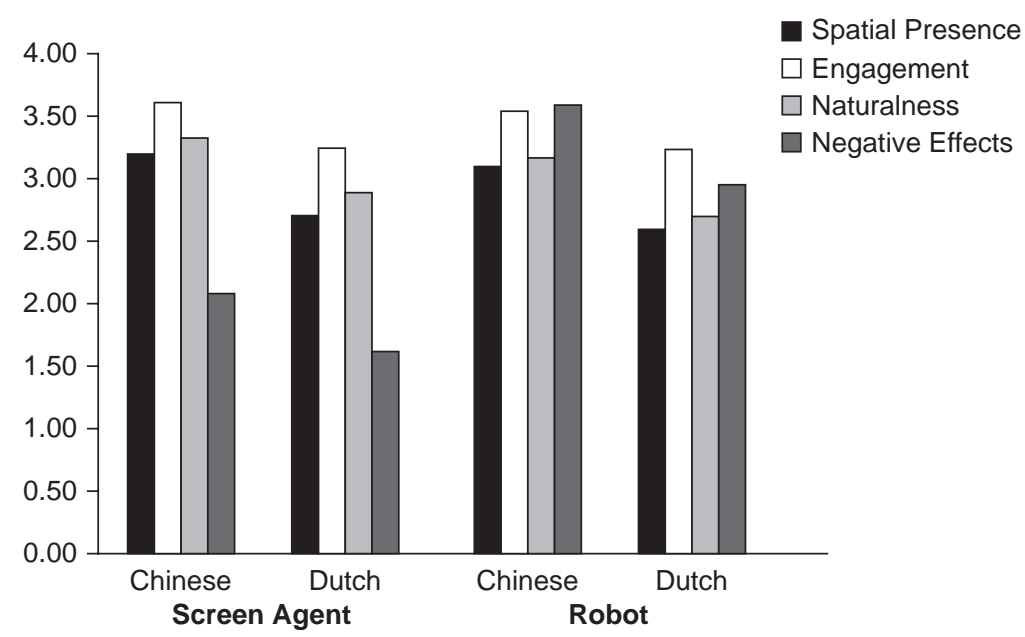

FIG. 6. Means in the culture and embodiment conditions. 


\section{Discussion}

\section{Culture effects}

The participants' cultural background clearly influenced the measurements. Chinese participants perceived more presence than Dutch participants did in all conditions. This result is in line with the results of Chua et al. ${ }^{9}$ It appears that the Chinese take a more holistic view, thereby appreciating the distributed media presentation more than the Dutch. As Chua et al predicted, the Chinese and Dutch allocated attention resources differently as they viewed the distributed environment. East Asians are known to live in relatively complex social networks. ${ }^{15}$ It is essential for them to consider the context in which events happen. Also, the results of Sacau et al. ${ }^{6}$ appear to be confirmed. The more agreeable Chinese perceived more spatial presence. One might suspect that the more agreeable attitude of the Chinese led them simply to be more polite in answering the questionnaire. However, our measurements show that they also gave higher scores to Negative Effects and therefore did not simply respond politely.

Note that in the Dutch culture, it is important to reach and maintain "consensus," a social phenomenon known as the Dutch "polder model,"16 which dates to the Middle Ages when it was necessary for people to compromise their own interests and to cooperate in order to keep the polders from being flooded. This consensus culture seems to be similar to agreeableness in Chinese culture. However, in Dutch culture, when there are no conflicts among people, consensus is not necessary and hence individualism takes the place to maximize the individual interests, which happens to be the case in our study where there was only one single user interacting with the system.

None of Hofstede's culture dimensions ${ }^{5,17}$ appear relevant to presence at first glance. However, one might speculate that the long-term orientation in Chinese culture would result in more patience and tolerance toward imperfections. In our case, the Chinese participants might have more easily tolerated the noise emitted by the robot and the occasional visibility of a microphone in the movie. Further studies are necessary to investigate this issue.

\section{Embodiment effects}

The influence of embodiment on all measurements does not conform to the expected results defined in the construct of presence. According to Lessiter et al.,13 "Whilst in the current study Negative Effects was not strongly correlated (positively or negatively) with Engagement or Ecological Validity, it was significantly but modestly (and positively) related to Sense of Physical Space." However, in our results, Spatial Presence and Naturalness are higher in the ScreenAgent condition, while Negative Effects were higher in the Robot condition. Negative Effects appear to have been affected by something other than presence.

During the experiment, the robot's motor emitted noise, which caused the participants to look at it. Clearly, the robot emphasized the participants' feeling of being in the room and not in the movie and thereby reduced the presence experience.

The participants frequently switched between looking at the movie and the robot, and hence their attention was divided. This switching made it hard for the users to stay focused and might have caused the high negative experience.
Eggen et al. ${ }^{17}$ showed that a divided attention space reduces the user's immersion.

\section{Effects of direct touching}

The different interaction methods (using a remote control or touching directly) had no influence on the measurements. This is to some degree surprising because the participants had to move actively to interact with the screen agent or the robot by leaning forward and touching it directly, where the actions and reactions are tightly coupled. With the remote control, the participants remained leaning back on the couch. The necessity to make a choice might have overshadowed the difference in physical movement.

\section{Future research}

The Chinese participants in this study had been living in the Netherlands and might therefore have formed a nonrepresentative group. They might have been to some degree westernized, but one could speculate that the effects observed in our study might be even stronger for Chinese participants who also live in China. This experiment would need to be run in China to gain full understanding of this issue. Furthermore, this study investigated several factors besides the cultural background of the participants. It might be beneficial to conduct a dedicated study on the influence of culture on presence. Such a study could then also cover more than the two cultures investigated in this study.

\section{Disclosure Statement}

The authors have no conflict of interest.

\section{References}

1. Freeman J, Lessiter J, IJsselsteijn W. An introduction to presence: a sense of being there in a mediated environment. Psychologist 2001; 14:190-4.

2. IJsselsteijn WA, Ridder Hd, Freeman J, Avons SE. Presence: concept, determinants, and measurement. Human Vision \& Electronic Imaging 2000; 3959:520-9.

3. Chang T-T, Wang X, Lim KJ. (2002) Cross-cultural communication, media and learning processes in asynchronous learning networks. In HICSS, 35th Annual Hawaii International Conference on System Sciences, Maui, Hawaii, pp. 113-22.

4. Sas $\mathrm{C}, \mathrm{O}^{\prime}$ Hare GMP. Presence equation: an investigation into cognitive factors underlying presence. Presence: Teleoperators \& Virtual Environments 2003; 12:523-37.

5. Hofstede G. Cultural constraints in management theories. Academy of Management Executive 1993; 7:81-94.

6. Sacau A, Laarni J, Ravaja N, et al. (2005) The impact of personality factors on the experience of spatial presence. In Slater M. ed. Proceedings of the 8th International Workshop on Presence. London: University College, 143-52.

7. McCrae RR, John OP. An introduction to the five-factor model and its applications. Journal of Personality 1992; 60:175-215.

8. Aarts E, Marzano S. (2003) The new everyday view on ambient intelligence. Rotterdam, Netherlands: Uitgeverij 010 Publishers.

9. Chua HF, Boland JE, Nisbett RE. Cultural variation in eye movements during scene perception. Proceedings of the National Academy of Sciences 2005; 102:12629-33. 
10. Bartneck C. (2002) eMuu-an embodied emotional character for the ambient intelligent home. Ph.D. Thesis, Eindhoven University of Technology, Eindhoven, Netherlands.

11. Hu J. (2006) Design of a distributed architecture for enriching media experience in home theaters. Ph.D. Thesis, Eindhoven University of Technology, Eindhoven, Netherlands.

12. Lombart M, Ditton T. At the heart of it all: the concept of presence. Journal of Computer Mediated Communication 1997; 3.

13. Lessiter J, Freeman J, Keogh E, et al. A cross-media presence questionnaire: the ITC Sense of Presence Inventory. Presence: Teleoperators \& Virtual Environments 2001; 10:282-97.

14. Lu M, Walker DF, Huang J. Do they look at educational multimedia differently than we do? A study of software evaluation in Taiwan and the United States. International Journal of Instructional Media 1999; 26:31-42.

15. Nisbett RE, Masuda T. Inaugural articles: culture and point of view. Proceedings of the National Academy of Sciences 2003; 100:11163-70.
16. Delsen L. (2002) Exit polder model? Socioeconomic changes in the Netherlands. Westport, CT: Praeger.

17. Eggen B, Feijs L, Graaf Md, Peters P (2003) Breaking the flow: Intervention in computer game play through physical and onscreen interaction. Proceedings of the Digital Games Research Conference 2003, 4-6 November 2003, University of Utrecht, The Netherlands.

Address reprint requests to: Dr. Christoph Bartneck Department of Industrial Design Eindhoven University of Technology Room HG 2.51, Den Dolech 2

5612 AZ Eindhoven

The Netherlands

E-mail: c.bartneck@tue.nl 